\title{
Schaut nur hinein ins volle Leben ...
}

David Künzler

Korrespondenz:

Dr. med. David Künzler Jakob-Zürrer-Strasse 35 CH-8915 Hausen am Albis
«... und wo ihr's seht ist's interessant.» So fasste der Präsident der Vereinigung «Kunstausstellung der Schweizer Ärzte» die Vielfalt der ausgestellten Werke an der Vernissage zusammen.

In seiner Begrüssung erklärte Herr Romeo Paioni, Leiter Wissenschafts- und Aussenbeziehung, wie es zu Ausstellungen in den Räumen der Firma gekommen war: In Ergänzung und sozusagen als künstlerische Einbettung der wissenschaftlichen Arbeit, die hier geleistet wird, gab man Künstlern, primär intern, später auch geöffnet für nicht zur Firma gehörenden Kunstschaffenden, Gelegenheit, ihre Werke auszustellen und auch zu verkaufen. Der Verkauf war völlig von Novartis unabhängig, für die Ausstellenden rein privat. Es wurden und werden lediglich die Räume zur Verfügung gestellt.

David Künzler dankte für diese sehr schöne Möglichkeit, wo ein einmalig variables und interessantes Raum-Wand-Angebot vorhanden ist. Die Idee für die «Kunstausstellung» war und ist immer noch, malenden Ärzten Gelegenheit zu geben, auszustellen, und nicht primär, zu verkaufen. Seit Jahren wurden aber immer wieder auch Verkaufsausstellungen organisiert.

Kunst könne ja an sich nicht definiert werden. Vielleicht sollte man eher sagen «Geschaffenes». Der Präsident fragte dann auch: «Was ist schön?» Schönheit sei ein Augenblick, wie aus einem Buch «Die Natur der Schönheit» hervorgehe. Ein Augenblick - ein Moment, eine Momentaufnahme? Vielleicht müsste man das Wort wörtlicher nehmen: Man müsse die Werke «anblicken», die Augen auftun, anschauen.

Ein 90jähriger Kollege von uns, Erwin Lejeune, hat in einem Rückblick auf sein Leben geschrieben, dass dann, wenn die Augen immer schwä- cher würden, man vom Sehen zum Schauen übergehen, die Welt also mit dem innern Auge anblicken müsse.

Da die Ausstellenden eigentlich nicht um grossen Profit verkaufen wollen, wird regelmässig ein Teil an eine Organisation abgezweigt, die Menschen hilft. Diesmal ist des zugunsten der UNICEF-Aktion: «Stopp der Mädchenbeschneidung».

Unsere Bilder zeigen wahrlich das volle Leben: Allgemeinpraktiker zeigen ganz konkrete Bilder, z.B. auf die Forschung hier im Hause hinweisend, oder versuchen Philosophie und Malerei zu vereinen. Chirurgen malen wunderschöne Ölbilder, die uns u.a. in den Süden entführen. Augenärzte «malen in den Sand» (Sandreliefs, koloriert), Dermatologinnen malen feinste Dessins und grosse farbenprächtige Exponate. Psychiaterinnen bilden Ballone, die nie platzen; andere malen delikate abstrakte Bilder. Andere Allgemeinpraktiker gestalten mächtige, kräftig gemalte Tableaux. Ein Gynäkologe kreiert in grosser Anzahl scheinbar immer ähnliche und doch im Detail ganz verschiedene «Variationen über ein Thema».

Zwölf Künstler haben total 71 Werke ausgestellt, eine faszinierende Schau, wirklich das «volle Leben». Eine kleine Anzahl ist hier zu sehen.

Die Ausstellung kann besucht werden in den Eingangshallen der Gebäude WKL-125 und WKL-135 der Novartis Basel, Porte 15, Klybeckstrasse. Kontaktperson: Frau Florence Fricker, Sekretariat Dr. Romeo Paioni.

Besuchen Sie auch unsere Homepage www.aerzte-kunst.ch. 


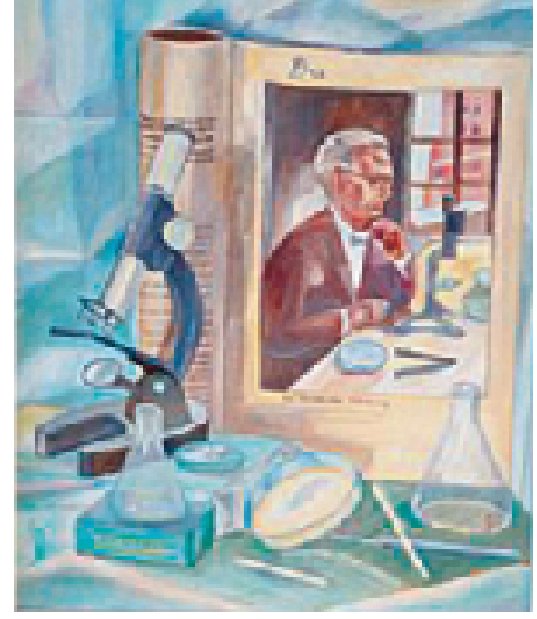

U. Siegfried: Stillleben mit «Du».

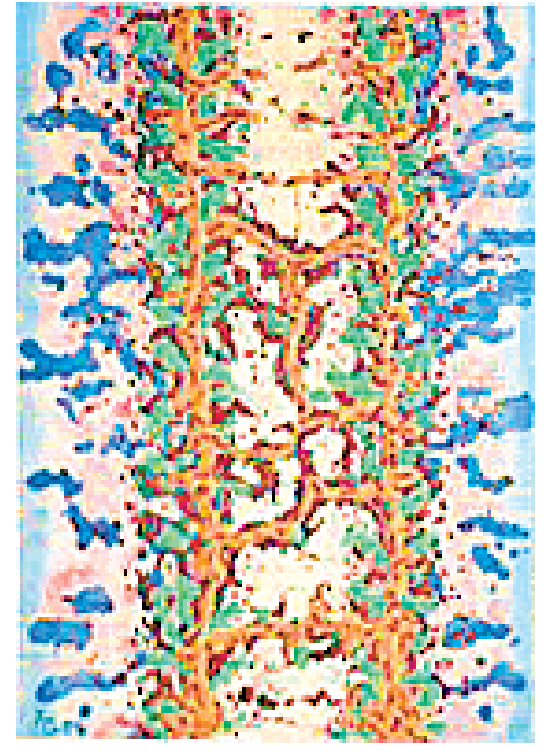

Frank Gafner: Sprossenland.

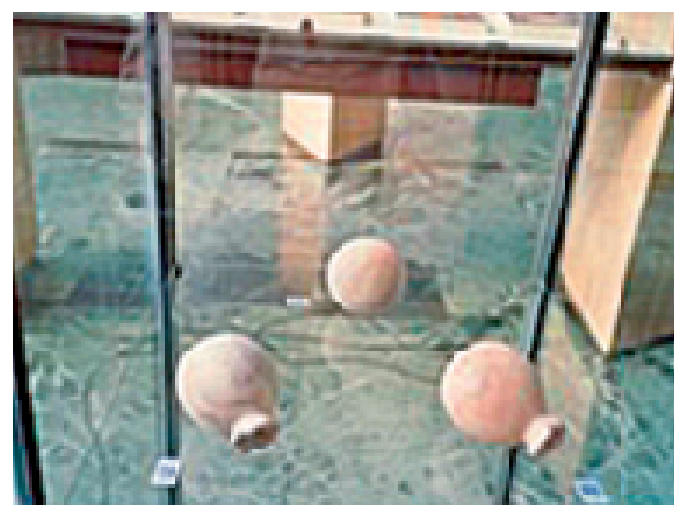

Regula Altorfer: Luftballone (Speckstein).

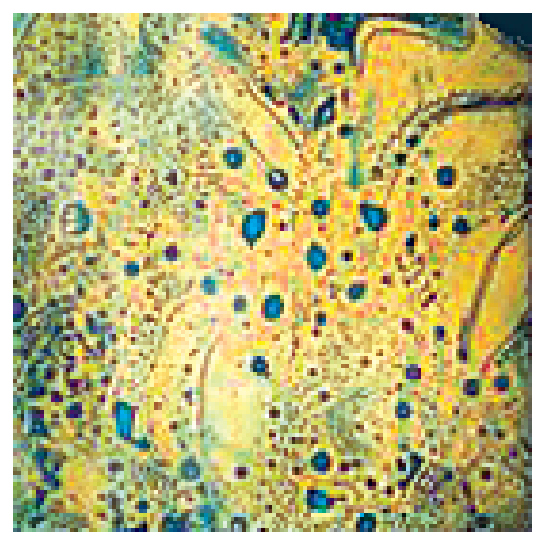

Joanna Stäger: Allegro non troppo (Radierung). 